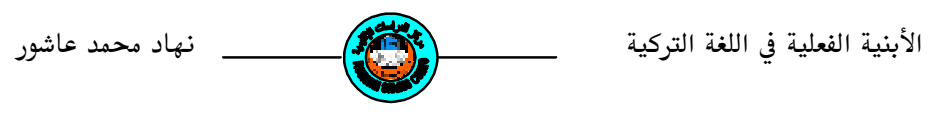

Türkçede yapım ekleri

\title{
System of Inflections and derivertion in Turkish
}

\author{
!llanguage \\ Nibad Mobammed Ashoos Assistant \\ lectuser -Department of Turkish Language- \\ College of arts- university of Mosul
}

\begin{abstract}
It should be necessary for any researcher to give some information (notification) about sufix in Turkish language.

Suffixes: aer syllables without meaning and couldn't used be alone, but if they are concatenated with the root words, then they sould have meaning and function.

Suffixes are divided due to their function into two categories:

A: Derivative Suffixes.

B: Conjugate Suffixes.

What concerns me in this research is derivative Suffixes, which chang the meaning and the origin of the word, when they are added (concatenated) to the roots of the words.

There are four kinds of derivatives Suffixes which they are:

1) Suffixes which change the word as a noun into another noun.

2) Suffixes which change the word as a noun into a verb.

3) Suffixes which change the word as a verb into a noun.

4) Suffixes which change the word as a verb into a verb.
\end{abstract}




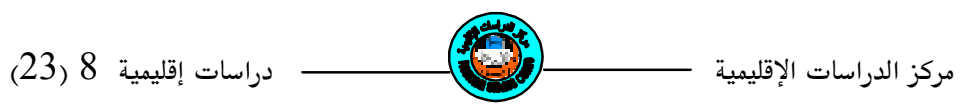

\section{$\ddot{O} n$ söz}

Ekler: Kelimenin bünyesindeki ikinci temel unsure ise görevli unsurlerdir. Demek ki ekler kendi başlarına bir anlamı olmayan ve kullanılmayan, ancak köklere eklenmek suretiyl kullanılabilen ve anlamla ilgili bir görevi bulunan şekillerdir. ${ }^{(1)}$

Eklerin genel olarak önemli bir rolü olduğundan dolayı Türkçe dilinde en çok işleyisli eklere değinmek hoşlandım.Bu yüzden bu araştırmada yapım eklerinde olan her ekini kısaca ve faydalı bir biçimde örneklerle açıkca belirtim.Öylece yapım ekleri yaptıkları yeni taban kelimenin cinsine göre isim yapan ve fiil yapan ekler iki yönlü sınıflandırdığımız da dört türlü yapım eki ortaya çıkar.

\section{Isimden isim yapan ekler.}

II.Isimden fiil yapan ekler.

III. Fiilden isim yapan ekler.

IV.Fiilden fiil yapan ekler.

\section{!!Giriş}

Kökler kelimelerin yapısında anlamlı ve görevli olmak üzere iki çeşit unsur bulunarak bunlardan anlamlı unsurlar tek başlar-1na kullanıl abilirler. Kelimenin yapısı bozulmadan, yapım ve çek-im eklerini çıkardıktan sonra, daha küçük birimlere ayrılamayan ve temel anlamı taşıyan bu unsurlara kök denir ${ }^{(2)}$.

Türkçede ekler belli bir sıraya göre kökten sonra getirilebilir. Türetmeler (yapım ekleri) ve çekim şekilleri eklerle yapıldığın-dan Türkçe dilinde ekler büyük bir öneme sahiptir. Köklerden gövdelerin türemesi Türkçede tamamıyla bir kök genişlemesi şeklinde olur. Köklere özel ekler getirilerek gövdeler yapılır. Bu ekler yapım ekleridir. Yani gövdeler köklerle yapım eklerinden teşkil edilir ${ }^{(3)}$.

Demek ki dilde özel kelime yapma yolları vardır. Dilin kelime yapma sartları şu üç noktada toplanır. Kök ve gövde. Yapım eki ve yapım şeklidir. 


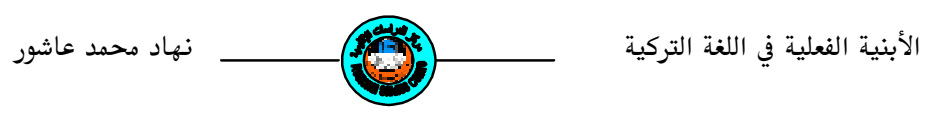

!!

\section{Isimden isim yapan ekler:}

Isim kök ve gövdelerinden isim yapmak için kullanılan yapım ekleridir. Bu ekler isim köklerine,isimden yapılmış isim gövdeLerine ve fiilden yapılmış isim gövdelerine eklenirler ${ }^{(4)} \mathrm{Bu}$ ek-

Leri başlıca işleyişlerine göre şu şekilde sırayabiliriz:

1. Lik,Llk,luk,lük: Bu ek isimden isim yapan eklerinin en işlek eklerinden sayılır. Işlevleri şunlardır:

Yer, isim yapar: ağaçlık, kömürlük, çöplük, taşlık

Alet,eşya isim yapar: Gözlük, tuzluk, önlük, dizlik.

Topluluk isim yapar :Genclik, türklük .

Meslek isim yapar :Müdürlük, öğretmenlik.

Yalın isimler yapar :Güzellik,iyilik, bağlılık .

Bazı kelimelerde slfat olarak kullantlan isimler yapar:

Yazlık ev, haftalık program, günlük iş.

2. $\boldsymbol{C} \boldsymbol{\imath}, \boldsymbol{C} \boldsymbol{i}, \boldsymbol{C u}, \boldsymbol{C u ̈}, \boldsymbol{C} \boldsymbol{u}, \boldsymbol{C} \ddot{u}:$ Her türlü ismin sonuna gelir ${ }^{(5)}$ Işlek Bir ektir işlevleri şunlardır:

Meslek ve iş isimleri yapar:Avc1, kitapçı, yolcu.

Bir işin alışkanlık haline getirdiğini gösterir: Yalancı, inatçı.

3. $\boldsymbol{L i}, \boldsymbol{L \imath}, \boldsymbol{L u}, \boldsymbol{L u ̈ :}$ Sıfat olarak isimler yapar: Neşeli, dertli,analı.

4. Siz , Siz , Suz , Süz :Bu ek ( li, li, lu, lü) ekinin olumsuzudur.

Evsiz, essiz, tuzsuz ,yağsiz,-------------.

5. Cik , Cik ,Cuk ,Cük :Küçültme, sevgi, acıma bildirir, hastalık, bitki alet ve yer isimleri yapar: Gelincik ,küçücük, gölçük.

6. Cak,Cek :Küçültme, sevgi ifadesi verir, sıfat ve zarf yapar:

Ailecek, büyücek, evcek.

7. Că̆gz, Ceğiz: Küçültme, sevgi, zavallılık bildirir. Adamcağız, Kadıncağız, hayvancağız . 


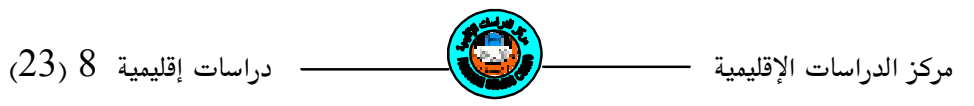

8. Ca, Ce , Ça , Çe :Dil ve lehce isimleri yapar:Turkce,Almanca.

9. Daş, Deş: Eşlik, ortaklık, bağlık bildiren isimler yapar:Arkadeş, Vatandaş, yurttaş.

10. Inci,Inc, uncu üncü: Asıl sayı isimlerindendir. Sira say1 isimler yapar:Yedinci, birinci, sonuncu.

11. Ar ,er/şar ,şer: Asıl sayı isimlerinden dağıtma sayı isimleri Yapar: Yedişer, beşer,ikişer.

12. $Z$ : Bu ekte iki işlev yönü var;ilki,Topluluk sayı isimleri Yapar. Ikiden sekize kadar olan sayılara gelir. Ikiz,beşiz, üçüz ,altuz,----------.Ikincisi ise benzerlik bildirir:boynuz< Boyun-u-z gibi. ${ }^{(6)}$

13. Si ,sı ,su ,sü:Benzerlik,gibilik ifade eder.Erkeksi,çocuksu, Kadınsı.

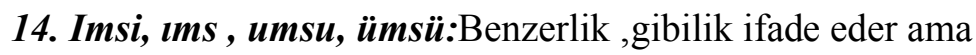
Tat ve renk isimlerine gelir. Ekşimsi,mavimsi,yeşilimsi.

15. Mtırak: Bu ek aynı \{imsi,ımsı, umsu, ümsü\} eklerinin görevindedir. Ekşimtirak, acımtırak.

16. $\mathbf{L i}, \boldsymbol{l} \boldsymbol{l}, \boldsymbol{l u}, \boldsymbol{l u ̈ i}: \mathrm{Bu}$ ek iki isim arasında Bir bağ görevi görür. Aşağı yukarı "ve" anlamındadır,Irili ufaklı, büyüklü küçüklü, Geceli gündüzlü, $\mathrm{vb}^{(7)}$.

17. Layın,Leyin :Bu ek vakit isimlere gelir.Ünlü uyumuna uymaz. Sabahleyin, akşamleyin,geceleyin.

18. Culayın, cileyin:Benzerlik,gibilik ifade eder.Benceleyin Yani" benim gibi "anlamına gelir.

19. Sal ,Sel:Yer bildiren isimler yapar ve bu ek bügün yaygın Bir şekilde kullanılmıştır. $\left({ }^{8}\right)$ Kırsal, kumsal, belgesel,dugusal. Aşağıdaki ekler ise işlek olmayan isimden isim yapan ekleridir. Onları da şöyle strayabiliriz:

20. Ti,tı ,tu ,tü:Yalnız yansıma kelimelere gelir.Gürültü,işilti. 


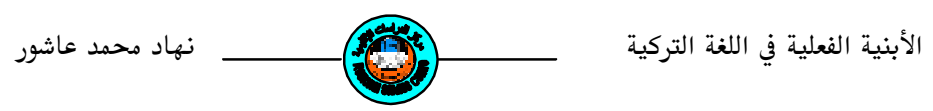

21. Gil ,gll, gul ,gül $\mid$ Kil ,kll,kul kül:Topluluk, ail ve ev ismi yapar ayrıca ilgi ifade eder.Oğuzgıl ,dayımgil ,annemgil.

22. Msar,mser:Sifatlara gelerek yine sifat yapmaktadır. KaramSar, kötümser,iyimser.

23. Dirik,dırık,duruk,dürük:Arac isimlere gelir.Boyun duruk.

24. Sul, sül: yoksul.

25. An, en: eren ,kızan, oğlan.

26. Kek: erkek.

27. Kan: Başkan.

28. $C$ : Atac,anac.

29. Ka,ke:Başka.

30. Cil,cul,cul, cüll Cil,cil,cul,cul : Evc1l, bencil, balıkc1l.

31. Man,men: Kocaman, kücümen.

32. Ac, ec: Kirac, topac, bozac.

33. Sin, sin: Sarsin, goksin.

34. $\boldsymbol{A k}$, $\boldsymbol{e}$ : Topak, başak.

35. $\boldsymbol{K}$ : Bebek, topuk.

36. $T$ : Eşit, yaşıt.

37. Az,ez: Ayaz, dayaz.

38. Ey: Güney, küzey.

39. La , le: Kışla, yayla.

II:Isimden fiil yapan ekler: Isim kök veya gövdelerinden

Fiil yapmak için kullanılan eklerdir ${ }^{(9)}$. Daha önce işlekli ekleri Siralayalim:

1. La , le: $\mathrm{Bu}$ ek en işlek ektir ve bazı kelimelerde (la,le) ile yapılan Fiil gövdeleri tek başlarına kullanılmayıp $(n, s ̧, t)$ eklerini alarak ortaya çıkmaktadır $^{(10)}$. Canlan, iyiles, kirlet, adileş.

2. $\boldsymbol{A l}, \boldsymbol{e l}: \mathrm{Bu}$ ek geçişsiz fiillerdir. Azal, yönel, görel. 


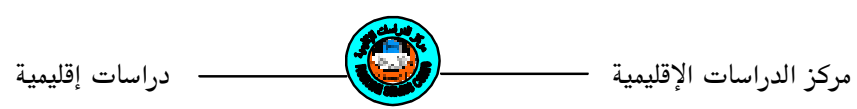

3. $\boldsymbol{A r}$, er: Bu ek renk isimlerinden fiil yapar. Akar, bozar.

4. Kir , kır , kur , kür ve R: Bu ekler yansıma kelimelere gelir.

Bağır, çağır, aksır, haykır, fişkır, püskür.

En az işlekli olan ekler ise de şunlardır:

5. $\boldsymbol{L}$ :Incel, kisal, doğrul.

6. A,e: Yasa, türe, boşa.

7. $K$ : Birik, gözuük.

8. Sa, se :Susa, önemse.

9. Msa, mse:-Azımsa, benimse.

III.Fiilden isim yapan ekler: Fiil kök veya gövdelerinden

Isim türeten eklerdir ${ }^{(11)}$. Türkce dilinde pek çok fiilden isim yap-an ek bulunmaktadır. Işlek ekleri başlıca şunlardır:

1. Mak, mek: Bu ek mastarlar meydana getirir.Esas işlevi hareket isimleri yapmakla birlikte, bazen somut anlamda isimler de yapar ${ }^{(12)}$.

yemek, kaymak, çakmak, olmak, batmak, saymak, kapatmak.

2. Ma ,me: Bu ek bütün fiil kök ve gövdelerine getirilir. Işlevi iş Isimleri yapar ${ }^{(13)}$. Gülme, unutma, okuma, bekleme.

3. Iş, ış, uş, üş̧: Bu ek bütün kök ve gövdelerine getirilir daha çok Hareket ve oluşun tarzını bildirir. Buluş, görüş, arayış, gösteriş.

4. Ici,ıcı,иси, ӥcü: Bu ek cokluk, asırılık, süreklilik bildirir. Alıc1, Kalıc1, yapıc1, gezici.

5. $\boldsymbol{M}$ : Nesne isimleri yapar.Giyim, doğum, biçim.

6. $\boldsymbol{K}$ : Çeşitli nesneleri karşılayan isimler yapar. Acık,yanık,tanık

7. $\boldsymbol{A} \boldsymbol{k}$, $\boldsymbol{e k}$ : Yer,alet ve sıfat isimleri yapar. Konak, durak, uçak.

8. $\boldsymbol{N}$ : Fiilden daha çok yapılanı ifade eden isimler yapar. Ekin, Gelin, akın, tütün.

9. Gi ,gı,gu,gü,ki,kı,ku,kü:Çok kullanılan bir ektir. Bilgi, atk1 


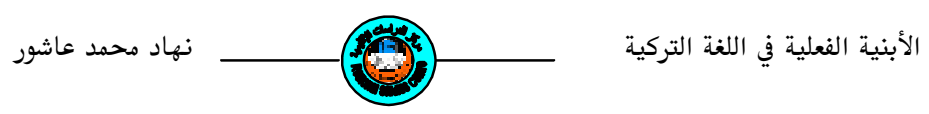

Duygu, uyku, örgü, dergi, sergi.

10. I, $\boldsymbol{\imath}, \boldsymbol{u}, \ddot{u}$ : Alet, somut ve soyut isimleri yapar. Doğu,korku, olcu, bat1.

11. $\boldsymbol{T i}, \boldsymbol{t} \boldsymbol{t}, \boldsymbol{t} \boldsymbol{u}, \boldsymbol{t} \ddot{\boldsymbol{u}}$ :Bu ek daha çok dönüşlülük (n) eki almış, dönüşLü fiil eklerine getirilir ${ }^{(14)}$. Cıkıntı, görüntü, sıkıntı, uzuntu.

12. Gin, gın,gun, gün $\backslash$ kin, kın, kun, kün: Bu ek büyütme ve asirilik

Anlamı verir daha çok sıfat olarak kullanılır, Düzgün, sürgün, tutkun, aşkın.

13. Gan,gen,| kan,ken : Tek heceli fiillere getirilmez. Işlevinde Kuvvetli bir asırılık vardır.Alıngan, unutkan , calışkan. Aşağıdaki eklerse fiile gelip isim yapan ekleridir.Ama az işlek olarak kullanılır.

14. gic,gıc|guc,güc: Bu ek değişik anlamlara isimler yapar. Bilgic dalgıc ,başlangıc.

15. gac,gec,|kac,kec:Bu ek isim ve sifat yapar .Utangec, yüz gec süzgec.

16. Agan, agan: Sureklilik ifade eder.Olagan,yatagan,gezegen. Aşağıdaki ekler sıfat fiil ekleridir ve kalıcı isimler de yapar. Onları da örneklerle belirteceğim.

17. An,en :Carpan, dözen, kıran.

18. Ar ,er,| ur,ür:Yazar,keser,düşünür.

19. Miş, mış, $m$ uş, müşs:Dolmuş, gecmiş,yemiş.

20. Acak,ecek: Gelecek,yakacak, içecek.

21. Maz,mez: Korkmaz,solmaz,tükenmez,yılmaz.

22. Dik,dık,duk,dük,|tik,tık,tuk,tük: Bildik, tandık, gördük, okuduk

23. $R$ : Gelir, yarar.

Aşağıdaki eklerse az işlekli olduğundan dolayı onları sadece strayayalım: 


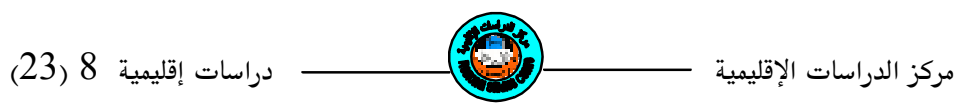

24. Ga, ge: Bilge, bölge, dalga, gösterge.

25. C: Inanc,kıskanc, gülünc,kazanc.

26. T: Geçit, yoğurt, umut, asit.

27. Si,sı,su,sü: Yats1, tutsu.

28. Anak,enek: Görenek, gelenek, sağanak.

29. Amak,emek: Kacamak, basamak.

30. Mik,mık,|muk,mük: Kiymik, ilmik, küsmük.

31. Ac,ec: gülec, görec.

32. Am,em:Tutam,susam.

33. Alak,elek:Asalak,cökelek

34. Arı,eri: uçarı.

35. Amac,emec:Dönemec.

36. Mac,mec: Y1rtmac,bulamac

37. Bac,bec: Dolanbac,saklanbac.

38. Sak,sek: Tutsak.

39. Man,men :Azman, gocmen.

40. Mur,mur: Yağmur.

41. Maca,mece: Bulmaca,bilmece,koşmaca.

42. Ca,ce :Eglence, sakınca, düşünce,güvence.

43. A,e:Sopa,oya,kese.

44. Di,dı,du,dü,| ti,tı,tu,tü:Geçmiş zaman ekidir.kalıcı isimler de yapar.Kulbastı, gündöndü, zipçikti.

IV. Fiileden fiil yapan ekler: Fiilden fiil türeten ekler,fiil

Kök veya gövdelerinden fiil yapan eklerdir.Bunların çoğu

Fiil yapan eklerdir ${ }^{(15)}$. Bu eklerin eklerini basıt ve özet bir biçimde şöyle de zikredebiliriz:

1. Ma,me \{olumsuz eki\}: Bu ek bütün fiil ve gövdelerine gelerek olumsuz fiiller yapar. Gitme, yapma, oturma, oynama, gelme 


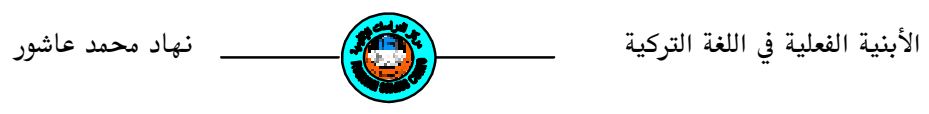

2. $\boldsymbol{N}$ \{dönüşlük $\boldsymbol{e k i \} : B u ~ e k ~ g e n i s ̧ ~ b i r ~ s ̧ e k i l d e ~ k u l l a n ı o r . I s ̧ l e v i , ~}$ Kendi kendine yapma veya olma ifade eden fiiler yapmakta$\operatorname{dir}^{(16)}$. " $N$ " ekine dönüşlü eki demeğinin sebebi çünkü bu ekin karşıladığı hareket,o hareketi yapan veya olan nesnenin üzerine döndüğündendir.Bu ekle yapılan fiilere dönüşlü fiiller ve (n) ekine de dönüşlülük eki denir ${ }^{(17)}$. Örnekler:Kapandı, dövündü, gezin, giyin, taran, soyun, silkin. Ama " $n$ " ile yapılan fiillerin bir kismi dönüşlü değil, mechulluk ve pasiflik ifade eder. Söylen, delin, yürün.

3. L\{pasiflik ve mechlluk eki\}: Bu ek geçişsiz fiillerden mechul,geçişli fiillerden pasif fiiller yapar ${ }^{(18)}$. Mechul fiiller özne istemeyen yani gösterdiği hareket kimin yaptığı belli olma- yan fiillerdir. Durul, gulun, kalk1l.

Pasif fiiller ise, fiiler özne alırlar, ama bu özne hareketi yapan değildir,hareket özne üzerine yapılmış olur ${ }^{(19)}$. Acıl, kesil, duyul, sürül, bozul.

4. $\boldsymbol{S}$ \{işteşlik eki\}: Ortaklasma fiiler daha çok geçişsiz tabanlardan yapılmış görünürler,geçişsiz olurlar ve nesne almazlar ${ }^{(20)}$. Dövüş,görüş,sözleş.

5. Ettirgenlik (faktitif)ekleri: Fiilden fiil türeten eklerinin bir k1smı yaptırma ve oldurma ifade eden fiiller yapar .

\section{Ettirgenlik ekleri başılıca şunlardır:}

1. $\boldsymbol{R}$ : Bu ek ünsüzle biten fiillerin bir kısmına gelir,ama ünlü ile biten fiillere gelmez. şaşır ,geçir ,yatır, taşır.

2. $\boldsymbol{T}$ : Işlek bir ettirgenlik ekidir:Söylet,yükselt,ürküt,yürüt,azalt

3. Dir, dir, dur, dur, tir, tir, tur, tur: Islek bir ektir, isleklik alani unlu ile bitten tek heceli fiillerle, unsuz ile bitten butun fiil ve govde- leri içine alır ${ }^{(22)}$. Bildir, saydır, kaptır, biriktir. 


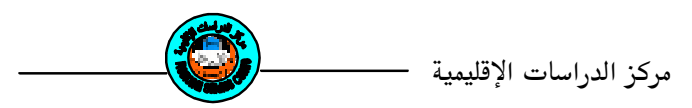

4. Ar,er :Işlevi çok azdır. Kopar ,çıkar.

5. Dar ,der : Işlek değil. Döner ,gider .

6. $\boldsymbol{U} \boldsymbol{r}$, ür:Fazla işlek olmayan. Gocur, doyur.

7. Ala ,ele :Kuvvetlendirme işleviyle fiiler türetir.

Kovala, sasala , esele.

$\boldsymbol{8} . \boldsymbol{I}, \boldsymbol{l}, \boldsymbol{u}, \ddot{\boldsymbol{u}}$ : Fiilden fiil türeten eki ama çok işlevli olunmayan.

Kazı, çiti.

9. Msa ,mse: Çok kullanılmayan bir ektir.Gülümse.

10. $Y$ : Işlek değildir. Sadece bir iki örnekte görünebilir.

Köy, toy gibi. 


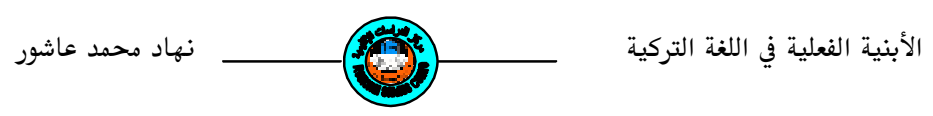

\author{
الأبنية الفعلية في اللغة التركية \\ نهاد محمد عاشور \\ مدرس مساعد - قسم اللغة التركية- كلية الآداب - جامعة الموصل
}

مستخلص البحث

تعتبر اللغة التركية من اللغات الالتصاقية التي تعتمد على اللواحق في اشتقاق الكلمات. واللواحق

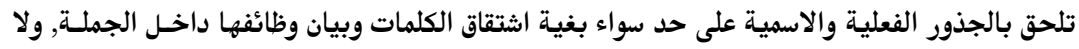
يمكن استعمالها مجردة دون إلحاقها

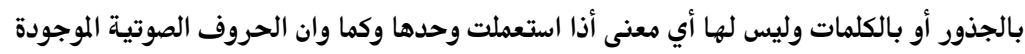
في اللواحق تخضع لقاعدة التوافق الصوتي.

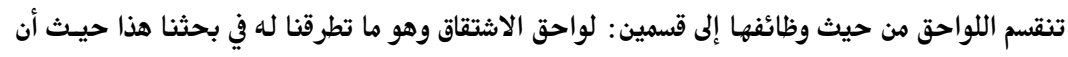

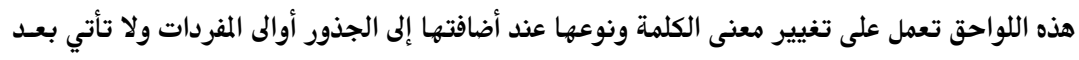

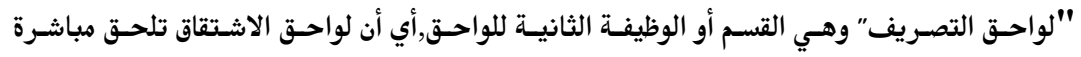
بالجذور.وتوجد في اللغة التركية أربعة أنواع من لواحق الاشتقاق:

$$
\text { د. د. لوال لواحق اشتقاق أسم من أسم أخر. }
$$




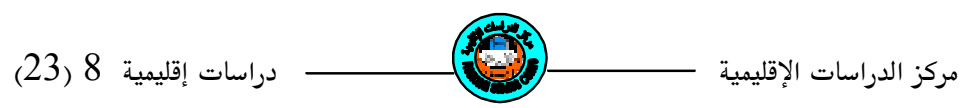

\section{DIPNOTLAR}

(1) Mustafa Özkan, Osman Esin, Hatice Tören, Yüksek Ogretimde Türk Dili, Filiz kitap evi, Istanbul 2001,s. 466.

(2) a.g.e.s.463.

(3) Muharrem Ergin, Türk Dilbilgisi, Edebiyat Fakültesi basım evi, Istanbul 1958, s.129.

(4) A.g.e.s.135.

(5) A.g.e.s.138.

(6) Mustafa Özkan, a.g.e.,s.486.

(7) Mahmet Aydin,Türk Dili,Dil ve Edebiyat dergisi, Aralık sayı 588,1995 ,s.64.

(8) Muharrem ,Ergin,a.g.e.s.100.

(9) Mustafa,Ozkan ,a.g.e.s.486.

(10) Hamza,Zülfikar,Yabancılar için Türkçe dersleri, Dilbilgisi, AnKara 1968,s.119.

(11) Tahsin,Banguoğlu,Türkçenin Grameri,Türk Tarih Kurumu basım evi, Ankara 1990, s.224.

(12) Şamil ,Fahri,Yahya,Türk dilini bilmeyenlere çağdaş Türkçe, Musul Üniversitesi,Edebiyat Fakültesi,2006,s.72.

(13) Mustafa,Özkan,a.g.e.s.490.

(14) Fazil ,Mehdi,Bayat,Türk dilbilgisi,Bağdat 1983,s.77.

(15) Mustafa,Özkan,a.g.e.s.494.

(16) Fazil ,Mehdi,Bayat,a.g.e.s.91.

(17) Mustafa,Özkan,a.g.e.s.495.

(18) Şamil,Fahri,Yahya,Çağdaş Türk Dilbilgisi,Musul Üniversitesi, Edebiyat fakültesi,1991.,s.304

(19) Mustafa,Özkan,a.g.e.s.495.

(20) Tahsin,Banguoğlu,Türkçenin Grameri,Türk Tarih kurumu Basım Evi,Ankara,1990,s.289.

(21) Mustafa,Özkan,a.g.e.s.495.

(22) A.g.e.s.496. 


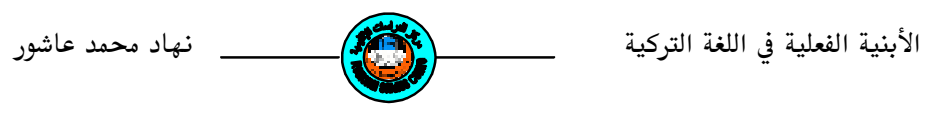

\section{KAYNAKLAR}

1. Fazıl, Mehdi, Bayat, Türk dilbilgisi, Bağdat 1983.

2. Hamza, Zülfikar, Yabancılar için Türkçe dersleri, Dilbilgisi, AnKara 1968.

3. Mahmet Aydın, Türk Dili, Dil ve Edebiyat dergisi, Aralık sayı 588, 1995.

4. Muharrem Ergin, Türk Dilbilgisi,Edebiyat Fakültesi basım evi, Istanbul 1958.

5. Mustafa Özkan, Osman Esin, Hatice Tören,Yüksek ögretimde Türk Dili, Filiz kitap evi, Istanbul 2001.

6. Şamil, Fahri, Yahya, Türk dilini bilmeyenlere çağdaş Türkçe, Musul Üniversitesi, Edebiyat Fakültesi, 2006.

7. Şamil, Fahri, Yahya, Çağdaş Türk Dilbilgisi, Musul Üniversi tesi, Edebiyat fakültesi, 1991.

8.Tahsin, Banguoğlu, Türkçenin Grameri, Türk Tarih kurumu Basım Evi, Ankara, 1990. 